\title{
Association between a history of child abuse and suicidal ideation, plans and attempts among Canadian public safety personnel: a cross-sectional survey
}

\author{
Sarah Turner MSc, Tamara Taillieu MSc, R. Nicholas Carleton PhD, Jitender Sareen MD, \\ Tracie O. Afifi PhD
}

\section{Abstract}

Background: A history of child abuse has been identified as a risk factor for suicidal behaviour in general population samples; however, it remains unknown how a history of child abuse and career-related trauma together are related to suicidal behaviour. This cross-sectional survey was designed to 1) estimate the prevalence of a history of child abuse among Canadian public safety personnel, 2) examine the associations between child abuse and suicidal behaviour, 3) examine the associations between career-related trauma and suicidal behaviour and 4) examine the cumulative and interactive effects of child abuse and career-related trauma on suicidal behaviour.

Methods: Data were drawn from a Web-based survey collected by the Canadian Institute for Public Safety Research and Treatment Team. Child abuse included physical abuse, sexual abuse and exposure to intimate partner violence in childhood. Suicidal behaviour included lifetime ideation, plans and attempt(s). We used logistic regression models to examine the associations between child abuse and suicidal behaviours, and cumulative and interaction models to test the relations between a history of child abuse and careerrelated trauma on suicidal behaviours.

Results: The survey completion rate was $49.3 \%(n=4199)$. A total of $2275 / 4073$ respondents $(55.9 \%)$ reported experiencing 1 or more types of abuse as a child. All types of child abuse and career-related trauma were significantly associated with suicidal behaviour (adjusted odds ratio 1.57-3.25). No cumulative or interaction effects were noted.

Interpretation: Both a history of child abuse and career-related trauma were significantly associated with suicidal behaviours; however, stronger relations were seen for the former. This finding may help the development of effective treatment and intervention strategies aimed at reducing suicidal behaviour among public safety personnel.

$\mathrm{P}$ ublic safety personnel in Canada include those working as police, firefighters, paramedics, correctional workers and call centre operators/dispatchers. ${ }^{1}$ These people experience substantial mental health problems ${ }^{2}$ strongly associated with suicidal behaviour., ${ }^{3,4}$ Recent Canadian estimates suggest that $27.8 \%$ of public safety personnel report lifetime suicidal ideation, $13.3 \%$ report lifetime planning, and $4.6 \%$ report a lifetime suicide attempt(s), ${ }^{5}$ rates that are higher than representative general population rates of $13.3 \%, 4.6 \%$ and $3.5 \%$, respectively. ${ }^{6}$ The Canadian Standing Committee of Public Safety and National Security identified suicide as important to address, along with risk factor research, to inform prevention strategies. ${ }^{1}$

Public safety personnel are commonly exposed to potentially traumatic events, ${ }^{7-9}$ which are also associated with sui- cidal behaviour. ${ }^{10-14}$ However, elevated suicidal outcomes were seen among nondeployed US soldiers, ${ }^{15}$ and precareer suicidality was elevated among US female firefighters. ${ }^{16}$ Accordingly, other possible risk factors, such as a history of child abuse, warrant research. A total of $32 \%$ and $48 \%$ of Canadian general and military populations, respectively, reported experiencing physical abuse, sexual abuse and/or exposure to intimate partner violence before the age of

Competing interests: None declared.

This article has been peer reviewed.

Correspondence to: Tracie Afifi, tracie.afifi@umanitoba.ca

CMAJ Open 2018. DOI:10.9778/cmajo.20170153 
16 years, ${ }^{17,18}$ and there is evidence that such abuse increases the risk for adult mental disorders and suicidality. ${ }^{17-23}$ The prevalence of childhood abuse among Canadian public safety personnel is unknown; however, it is known that cumulative traumatic exposure increases the risk for mental disorders and suicidality. ${ }^{24-26} \mathrm{We}$ engaged a large sample of Canadian public safety personnel to better understand factors associated with suicidal behaviours. Our objectives were to 1) estimate the prevalence of a history of child abuse, 2) examine associations between a history of child abuse and suicidal behaviours, 3) examine associations between career-related trauma and suicidal behaviours and 4) compute the cumulative and interactive effects of a history of child abuse and career-related trauma on suicidal behaviours.

\section{Methods}

\section{Data and sample}

Data were drawn from an open Web-based survey (Qualtrics, https://www.qualtrics.com/) of Canadian public safety personnel available online from Sept. 1, 2016, to Jan. 31, 2017.2,5 Survey participation was self-selected and voluntary, which made this a convenience sample. The survey modules were developed by the Canadian Institute for Public Safety Research and Treatment Team, which included the Canadian Association of Chiefs of Police, the Canadian Association of Fire Chiefs, the Canadian Association of Police Governance, the Canadian Police Association, the Correctional Service of Canada, the International Association of Fire Fighters, the Paramedic Association of Canada, the Paramedic Chiefs of Canada, the Royal Canadian Mounted Police and the Union of Solicitor General Employees, as well as the University of Regina, where one of the authors (R.N.C.) is employed. The other authors did not give input in designing the survey but were invited to collaborate with R.N.C. to design the research questions. The survey was piloted with undergraduate and graduate students before launch. Participation was solicited through emails sent by national public safety associations to currently serving members, and a link was posted on association Web sites. As well, the Minister of Public Safety and Emergency Preparedness prepared a public service announcement video that was available online. No incentives were offered for completing the questionnaire.

Respondents were given a random unique identifier to log in anonymously as often as needed to complete the survey. No identifying information was collected; therefore, there was no way of identifying unique visitors. The median time to complete the survey was 1.3 hours. Some respondents did not log out when stepping away from the computer, and therefore the range of completion times was very large and the mean was not calculated. Because there was no clear cut-off point to identify outliers, none were excluded. Data were exported directly from the Web site to an electronic database.

The survey design prohibited determining how many public safety personnel were successfully invited; therefore, we were not able to compute a traditional response rate. Instead, we computed a completion rate, indicating the proportion of respondents who completed the questionnaire modules included in the current analyses divided by those who started the survey.

\section{History of child abuse}

We measured a history of child abuse using 6 questions previously validated from the Childhood Experiences of Violence Questionnaire ${ }^{27}$ and employed in nationally representative Canadian surveys. ${ }^{28,29}$ The questions were categorized into physical abuse, sexual abuse and exposure to intimate partner violence as a child based on validated cut-offs. ${ }^{27}$ Question response options included "never," "1-2 times," "3-5 times," "6-10 times" or "> 10 times." We used 3 questions to measure physical abuse: 1) "How many times did an adult slap you on the face, hand or ears, or hit or spank you with something hard to hurt you?" 2) "How many times did an adult push, grab, shove or throw something at you to hurt you?" and 3) "How many times did an adult kick, bite, punch, burn you or physically attack you in some way?" A response option of 3 times or more on questions 1 and 2, and any response other than "never" for question 3, was coded as physical abuse. Any physical abuse was coded as exposure to at least 1 of the 3 experiences based on the above coding. We measured sexual abuse using the following 2 items: "How many times did an adult force you or attempt to force you into any unwanted sexual activity by threatening you, holding you down or hurting you in some way?" and "How many times did an adult touch you against your will in any sexual way? By this, we mean anything from unwanted touching or grabbing, to kissing or fondling." Exposure to sexual abuse was coded as any response other than "never" on either question. We measured exposure to intimate partner violence as a child using 1 item: "How many times did you see or hear any one of your parents, stepparents or guardians hit each other or another adult in the home? By adult, we mean anyone 18 years and over." A response option of 3 times or more was coded as exposure to intimate partner violence. In addition, we computed a dichotomous measure of any child abuse that classified respondents who reported experiencing 1 or more types of abuse into the "yes" category. The number of child abuse exposures was coded as none, 1 type, or 2 or more types.

\section{Career-related trauma}

Respondents were asked to indicate the frequency of witnessing or experiencing the following career-related traumatic events: 1) death in the line of duty, 2) serious injuries in the line of duty, 3) disaster or multiple-causality incidents, 4) incidents involving the unusual or sudden death of children or harm of children, 5) events that threatened their life or the life of a colleague, 6) incidents in which victims were relatives or friends or 7) suicide of a close colleague or superior. These questions were developed specifically for this survey. We created a dichotomous variable (yes/no) that classified respondents who reported experiencing 1 or more event into the "yes" category. ${ }^{30}$ 


\section{Suicidal behaviours}

To assess suicidal ideation, plans and attempts, respondents were asked 3 questions that have been previously used in Statistics Canada surveys ${ }^{28,29}$ and published in high-impact journals: 6,18 "Have you ever seriously contemplated suicide?" "Have you ever made a plan to attempt suicide?" and "Have you ever attempted suicide in your lifetime?" ${ }^{28,29,31} \mathrm{We}$ created 3 separate dichotomous (yes/no) variables to assess these behaviours.

\section{Statistical analysis}

Analyses were limited to correctional workers, call centre operators/dispatchers, firefighters, municipal or provincial police, paramedics and Royal Canadian Mounted Police. First, we used cross-tabulations and logistic regression with complete case analysis to determine the sociodemographic characteristics of the sample among those with and without any child abuse exposure. Second, we used crosstabulations to determine the frequency of each type of child abuse and any career-related trauma by public safety personnel category. We tested significant differences between each public safety personnel category using separate logistic regression models for each public safety personnel category as the reference. Third, we computed separate crosstabulations and logistic regression models to examine the relations between each child abuse type and lifetime suicidal ideation, plans and attempt(s), adjusting for sex, age (continuous), marital status (married/common-law/remarried, single, separated/divorced/widowed), region of residence (Western Canada/territories, Eastern Canada, Atlantic Canada), ethnicity (white, other), education (some postsecondary or less, university degree/4 years of college or higher), years of service in public safety (continuous) and employment category (municipal/provincial police, Royal Canadian Mounted Police, correctional worker, firefighter, paramedic, call centre operator/dispatcher). Fourth, we tested individual and cumulative effects of trauma exposure by creating a multilevel variable of mutually exclusive categories that included those who 1) did not report experiencing any child abuse or career-related trauma, 2) reported experiencing child abuse only, 3) reported experiencing career-related trauma only or 4) reported experiencing both child abuse and career-related trauma. We used logistic regression to measure the association between this 4-level variable and suicidal ideation, plans and attempt(s). Differences between the categories were tested with separate logistic regression models, with each level of the 4-level variable as the reference. Fifth, we tested individual and interactive effects of trauma exposure using logistic regression to examine the relations between any child abuse, career-related trauma and suicidal behaviours. To determine interactive effects, we computed an interaction term between child abuse and career-related trauma, and entered it into the model with the main effects. All cumulative and interactive analyses were adjusted for sociodemographic variables. Analyses were completed with Stata version 15.0 (StataCorp).

\section{Ethics approval}

The study was approved by the University of Regina Research Ethics Board, and informed consent was obtained online from each respondent before he or she began the survey.

\section{Results}

In total, 8520 respondents began the survey, and 4340 progressed far enough to complete at least 1 question on the child abuse module. After we excluded people from ineligible professions, the final sample comprised 4199 respondents, for a completion rate of $49.3 \%$. A completion rate sensitivity analysis comparing sociodemographic variables among those who had valid responses (yes/no) on the variables of interest in the current analyses indicated significant differences based on marital status and region of residence as well as for some age categories, years of service categories and public safety personnel types (Supplementary Table A1, Appendix 1, available at www.cmajopen.ca/content/6/4/E463/suppl/DC1). The percentage of missing data for each variable ranged from $0.3 \%$ to $8.7 \%$.

Over half $(2275 / 4073$ [55.9\%]) of respondents reported a history of child abuse. Specifically, 2018 (49.4\%) reported physical abuse, $583(14.1 \%)$ reported sexual abuse, and 368 $(8.9 \%)$ reported exposure to intimate partner violence as a child. The sociodemographic characteristics of respondents with and without a history of child abuse are presented in Table 1. Several variables were related to increased odds of having a history of child abuse, including older age, being separated/widowed/divorced, ethnicity other than white and more years of service (odds ratio [OR] 1.02-1.60). Compared to participants living in Western Canada/territories, those living in Atlantic Canada had lower odds of having a history of child abuse (OR 0.72, 95\% confidence interval [CI] 0.600.90). Compared to participants with less education, those who had a university degree or 4 years of college also had lower odds of having experienced child abuse (OR 0.78, 95\% CI 0.70-0.90). Compared to municipal/provincial police, correctional workers and paramedics had greater odds of having a history of child abuse (OR 1.23, 95\% CI 1.00-1.50, and OR $1.27,95 \%$ CI 1.00-1.60, respectively).

Table 2 provides the prevalence of a history of child abuse and career-related trauma by public safety personnel category. Significant differences between categories were noted for all types of child abuse; however, consistent trends appeared only for correctional workers and call centre operators/dispatchers. These groups were more likely than other public safety personnel to have experienced being pushed, grabbed or shoved, or having something thrown at them, sexual abuse, and 2 or more types of child abuse. Most respondents (3947 [94.0\%]) also reported experiencing careerrelated trauma, with correctional workers reporting the lowest prevalence (502 [84.9\%]).

The relation between child abuse types and lifetime suicidal ideation, plans and attempt(s) is shown in Table 3. The prevalence of lifetime suicidal ideation, plans and attempt(s) in the current sample was $26.6 \%(n=1118), 12.7 \%(n=534)$ and 


\begin{tabular}{|c|c|c|c|}
\hline \multirow[b]{2}{*}{ Variable } & \multicolumn{2}{|c|}{ Status; no. (\%) of respondents ${ }^{*} \dagger$} & \multirow[b]{2}{*}{ OR $(95 \% \mathrm{Cl})$} \\
\hline & $\begin{array}{c}\text { No child abuse } \\
n=1924\end{array}$ & $\begin{array}{c}\text { Child abuse } \\
n=2275\end{array}$ & \\
\hline \multicolumn{4}{|l|}{ Sex } \\
\hline Male & $1222(45.1)$ & $1490(54.9)$ & 1.00 \\
\hline Female & $570(42.3)$ & $778(57.7)$ & $1.12(0.98-1.3)$ \\
\hline Age, yr, mean \pm SD & $41.7 \pm 9.3$ & $44.5 \pm 8.9$ & $1.04(1.0-1.0)$ \\
\hline \multicolumn{4}{|l|}{ Marital status } \\
\hline Married/common-law/remarried & $1453(45.5)$ & $1741(54.4)$ & 1.00 \\
\hline Single & $181(44.1)$ & $229(55.9)$ & $1.06(0.9-1.3)$ \\
\hline Separated/divorced/widowed & $151(34.2)$ & $290(65.8)$ & $1.60(1.3-2.0)$ \\
\hline \multicolumn{4}{|l|}{ Region of residence } \\
\hline Western Canadał and territories & $962(43.5)$ & $1249(56.5)$ & 1.00 \\
\hline Eastern Canada§ & $580(42.4)$ & $787(57.6)$ & $1.05(0.9-1.2)$ \\
\hline Atlantic Canadaף & $239(51.6)$ & $224(48.4)$ & $0.72(0.6-0.9)$ \\
\hline \multicolumn{4}{|l|}{ Ethnicity } \\
\hline White & $1671(45.0)$ & $2039(55.0)$ & 1.00 \\
\hline Other & $112(34.6)$ & $212(65.4)$ & $1.55(1.2-2.0)$ \\
\hline \multicolumn{4}{|l|}{ Education } \\
\hline Some postsecondary or less & $1038(41.8)$ & $1444(58.2)$ & 1.00 \\
\hline $\begin{array}{l}\text { University degree/4 yr of college } \\
\text { or higher }\end{array}$ & $714(48.0)$ & $774(52.0)$ & $0.78(0.7-0.9)$ \\
\hline Years of service, mean \pm SD & $16.6 \pm 9.4$ & $18.6 \pm 9.3$ & $1.02(1.0-1.0)$ \\
\hline \multicolumn{4}{|l|}{ Public safety personnel category } \\
\hline Municipal/provincial police & $497(45.6)$ & $594(54.4)$ & 1.00 \\
\hline Royal Canadian Mounted Police & $480(46.7)$ & $547(53.3)$ & $0.95(0.8-1.1)$ \\
\hline Correctional workers & $234(40.6)$ & $343(59.4)$ & $1.23(1.0-1.5)$ \\
\hline Firefighters & $279(45.1)$ & $340(54.9)$ & $1.02(0.8-1.2)$ \\
\hline Paramedics & $218(39.6)$ & $332(60.4)$ & $1.27(1.0-1.6)$ \\
\hline Call centre operators/dispatchers & $90(43.1)$ & $119(56.9)$ & $1.11(0.8-1.5)$ \\
\hline \multicolumn{4}{|c|}{$\begin{array}{l}\text { Note: } \mathrm{Cl}=\text { confidence interval, } \mathrm{OR}=\text { odds ratio, } \mathrm{SD}=\text { standard deviation. } \\
\text { *Except where noted otherwise. } \\
\text { †Denominators vary as not all respondents answered all questions. } \\
\text { †British Columbia, Alberta, Saskatchewan and Manitoba. } \\
\text { §Ontario and Quebec. } \\
\text { qNew Brunswick, Nova Scotia, Prince Edward Island and Newfoundland and Labrador. }\end{array}$} \\
\hline
\end{tabular}

$4.4 \%(n=184)$, respectively (data not shown). All types of child abuse were related to lifetime suicidal ideation (adjusted OR 2.09-2.63), plans (adjusted OR 2.06-2.48) and attempt(s) (adjusted OR 2.38-3.25).

Cumulative models showed significant associations between child abuse only, career-related trauma only, or both child abuse and career-related trauma and suicidal behaviours (adjusted OR 1.84-7.12) (Table 4). Experiencing child abuse only and experiencing both child abuse and career-related trauma did not have significantly different associations with suicidal behaviour. However, the association between career-related trauma only and suicidal behav- iour was significantly smaller than that for child abuse only and that for child abuse and career-related trauma together.

Table 5 presents the individual and interaction effects of career-related trauma and a history of child abuse on suicidal behaviours. Career-related trauma was significantly related to lifetime suicidal ideation and plans (adjusted OR 1.57 [95\% CI 1.10-2.20] and 1.78 [95\% CI 1.10-2.90], respectively). After career-related trauma was controlled for, a history of child abuse remained significantly related to lifetime suicidal behaviours (adjusted OR 2.21-2.60). After a history of child abuse was controlled for, career-related trauma was no longer significantly related to suicidal behaviours. 


\begin{tabular}{|c|c|c|c|c|c|c|c|}
\hline \multicolumn{7}{|c|}{ Category; no. (\%) of respondents* } & $\begin{array}{c}\text { Significant } \\
\text { differences† }\end{array}$ \\
\hline $1880(46.0)$ & $482(44.2)$ & $440(42.6)$ & $280(48.5)$ & $305(48.9)$ & $278(50.0)$ & $95(45.5)$ & $\begin{array}{l}a<e \\
b<c, d, e\end{array}$ \\
\hline $831(20.4)$ & $205(18.9)$ & $198(19.3)$ & $144(25.0)$ & $121(19.4)$ & $104(18.7)$ & $59(28.8)$ & $\begin{array}{l}a<c, f \\
b<c, f \\
d<c, f \\
e<c, f\end{array}$ \\
\hline $2018(49.4)$ & $523(47.9)$ & $477(46.3)$ & $296(51.2)$ & $326(52.4)$ & $295(53.2)$ & $101(48.6)$ & $\begin{array}{l}a<e \\
b<d, e\end{array}$ \\
\hline $583(14.1)$ & $139(12.7)$ & $129(12.3)$ & $132(22.8)$ & $47(7.4)$ & $86(15.2)$ & $50(23.8)$ & $\begin{array}{l}a<c, f \\
b<c, f \\
d<a, b, c, e, f \\
e<f, c\end{array}$ \\
\hline $368(8.9)$ & $94(8.5)$ & $94(9.0)$ & $62(10.6)$ & $45(7.0)$ & $48(8.5)$ & $25(11.7)$ & $d<c, f$ \\
\hline $2275(55.9)$ & $594(54.4)$ & $547(53.3)$ & $343(59.4)$ & $340(54.9)$ & $332(60.4)$ & $119(56.9)$ & $\begin{array}{l}\mathrm{a}<\mathrm{c}, \mathrm{e} \\
\mathrm{b}<\mathrm{c}, \mathrm{e}\end{array}$ \\
\hline $598(14.9)$ & $139(13.0)$ & $132(12.9)$ & $124(21.9)$ & $70(11.5)$ & $90(16.5)$ & $43(21.0)$ & $\begin{array}{l}a<c, f \\
b<c, f \\
d<c, e, f \\
e<c\end{array}$ \\
\hline $3947(94.0)$ & $95.2(1061)$ & $1016(95.9)$ & $502(84.9)$ & $614(94.8)$ & $557(97.2)$ & $197(92.1)$ & $\begin{array}{l}c<a, b, d, e, f \\
d<e \\
f<b, e\end{array}$ \\
\hline $\begin{array}{l}\text { respondents } \\
0.05 \text { in the } p\end{array}$ & nce of a his & child abus & ny career-r & auma betw & ferent public & versonnel & gories based on \\
\hline
\end{tabular}

Interaction terms between career-related trauma and a history of child abuse on lifetime suicidal behaviours were not significant.

\section{Interpretation}

In this national survey including measures of childhood physical abuse, sexual abuse and exposure to intimate partner violence among Canadian public safety personnel, there are 4 novel findings. First, $55.9 \%$ of our sample reported experiencing child abuse. Second, correctional workers and call cen- tre operators/dispatchers had a higher prevalence of some types of child abuse than other public safety personnel. Third, all types of child abuse were significantly related to lifetime suicidal behaviour. Fourth, career-related trauma was significantly related to suicidal behaviour; however, stronger associations were seen for a history of child abuse.

Over half of our sample reported experiencing child abuse before 16 years of age. Although we were not able to statistically compare these estimates to those for the Canadian general population or military populations, the prevalence appears higher than that among the general population $(32 \%)$ 
Table 3: Associations between a history of child abuse and lifetime suicidal behaviours

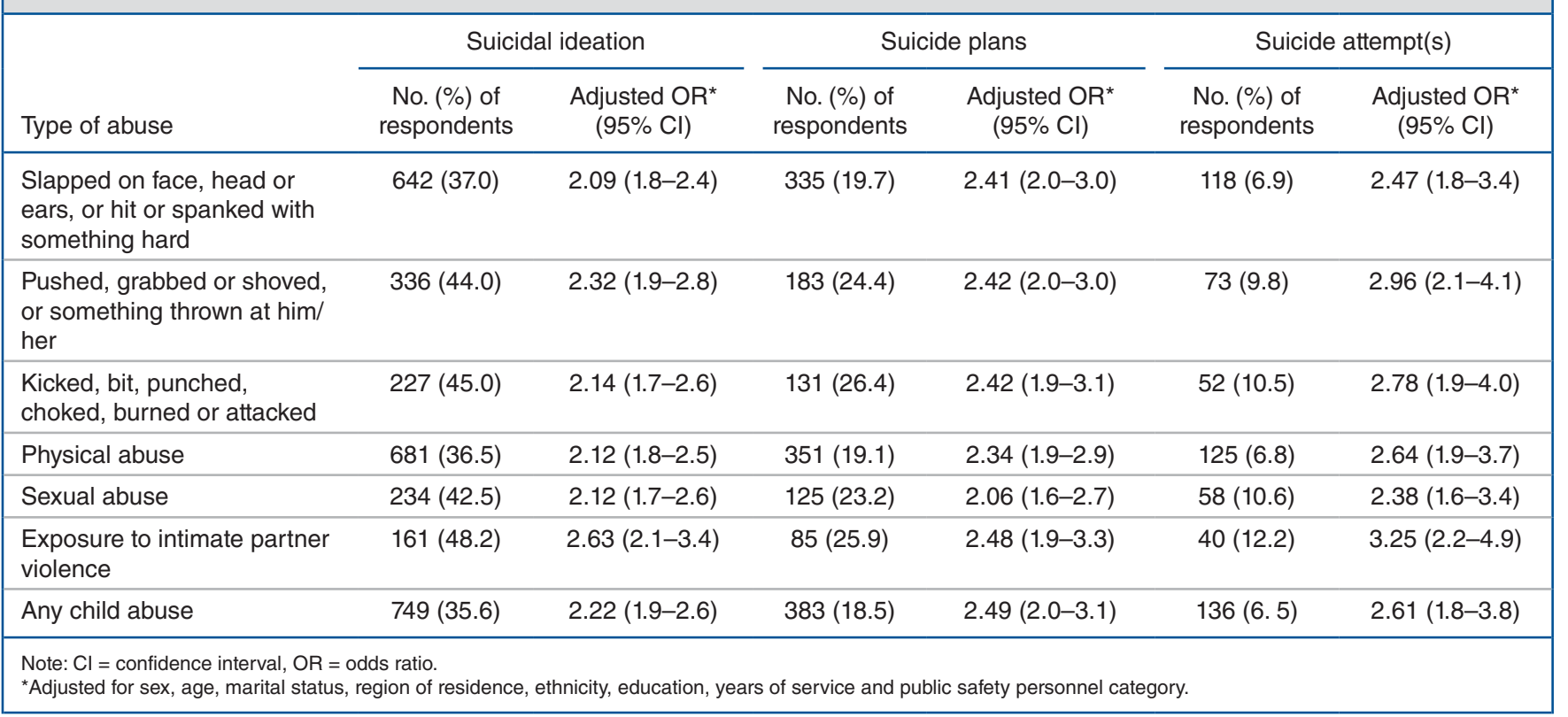

Table 4: Individual and cumulative effects of a history of child abuse and career-related trauma on lifetime suicidal behaviours

\begin{tabular}{|c|c|c|c|c|c|c|}
\hline \multirow[b]{2}{*}{ Abuse/trauma category ${ }^{*} \dagger$} & \multicolumn{2}{|c|}{ Suicidal ideation } & \multicolumn{2}{|c|}{ Suicide plans } & \multicolumn{2}{|c|}{ Suicide attempt(s) } \\
\hline & $\begin{array}{l}\text { No. }(\%) \text { of } \\
\text { respondents }\end{array}$ & $\begin{array}{l}\text { Adjusted OR } \ddagger \\
\qquad(95 \% \mathrm{Cl})\end{array}$ & $\begin{array}{l}\text { No. }(\%) \text { of } \\
\text { respondents }\end{array}$ & $\begin{array}{l}\text { Adjusted OR } \ddagger \\
\quad(95 \% \mathrm{Cl})\end{array}$ & $\begin{array}{l}\text { No. }(\%) \text { of } \\
\text { respondents }\end{array}$ & $\begin{array}{l}\text { Adjusted OR } \ddagger \\
\qquad(95 \% \mathrm{Cl})\end{array}$ \\
\hline $\begin{array}{l}\text { No child abuse/career- } \\
\text { related trauma }\end{array}$ & $16(12.7)$ & 1.00 & NP & 1.00 & NP & 1.00 \\
\hline Child abuse only & $31(31.6)$ & $3.33 \S(1.6-6.8)$ & $16(16.5)$ & $5.89 \S(1.9-18.5)$ & NP & $3.98 \S(1.0-15.5)$ \\
\hline $\begin{array}{l}\text { Child abuse and career- } \\
\text { related trauma }\end{array}$ & $718(35.8)$ & $3.97 \S(2.3-7.0)$ & $367(18.6)$ & $7.12 \S(2.6-19.7)$ & $127(6.4)$ & $3.80 \S(1.2-12.5)$ \\
\hline \multicolumn{7}{|c|}{$\begin{array}{l}\text { Note: } \mathrm{Cl}=\text { confidence interval, } \mathrm{NP}=\text { not presented because of insufficient sample size (i.e., } n<10 \text { ), OR = odds ratio. } \\
\text { *Mutually exclusive categories. } \\
\text { †Logistic regression was used to test for statistically significant differences between the 4-level child abuse/career-related trauma variable. Symbols indicate significant } \\
\text { differences between categories at } p<0.05 \text {. } \\
\text { †Adjusted for sex, age, marital status, region of residence, ethnicity, education, years of service and public safety personnel category. } \\
\text { §The relation between child abuse only and suicidal behaviours was not significantly different from the relation between both child abuse and career-related trauma and } \\
\text { suicidal behaviours. } \\
\text { १The relation between career-related trauma only and suicidal behaviours was significantly different from the relation between child abuse only and suicidal behavours and } \\
\text { both child abuse and career-related trauma and suicidal behaviours. }\end{array}$} \\
\hline
\end{tabular}

and comparable to that among the military population (48\%). ${ }^{18}$ Correctional workers and call centre operators/dispatchers reported a higher prevalence of some types of child abuse than other public safety personnel. Correctional workers had the lowest prevalence of career-related trauma. These results suggest that tailored interventions for public safety personnel may be warranted, but replication and extension of our results are necessary. In the interim, the high prevalence of a history of various types of child abuse among all public safety personnel should be recognized, and effective initiatives promoting trauma-informed care should be supported.

We also found a strong association between a history of child abuse and suicidal ideation, plans and attempt(s). Previous studies have similarly evidenced a robust association between a history of child abuse and suicidal behaviours in military ${ }^{18,32}$ and general population ${ }^{17,19,23}$ samples. This provides further support for the importance of preventing child abuse and recognizing a history of child abuse as an important factor related to suicidal behaviours. Career-related trauma was also significantly associated with suicidal behaviours, which is consistent with evidence that traumatic experiences, such as responding to a suicide attempt or death, ${ }^{33}$ traumatic work-related events ${ }^{34}$ or death of a fellow officer, ${ }^{10}$ appear related to increased suicidal behaviour. Cumulative and adjusted logistic regression models indicated that, although career-related trauma was associated with suicidal behaviour, a history of child abuse was consistently more strongly associated with lifetime suicidal behaviours. 


\begin{tabular}{|c|c|c|c|}
\hline \multirow[b]{2}{*}{ Model } & \multicolumn{3}{|c|}{ Adjusted $\mathrm{OR}^{\star}(95 \% \mathrm{Cl})$} \\
\hline & Suicidal ideation & Suicide plans & Suicide attempt(s) \\
\hline 1. Career-related trauma & $1.57(1.1-2.2)$ & $1.78(1.1-2.9)$ & $1.22(0.6-2.3)$ \\
\hline 2. Child abuse & $2.22(1.9-2.6)$ & $2.49(2.0-3.1)$ & $2.61(1.8-3.8)$ \\
\hline \multicolumn{4}{|l|}{3.} \\
\hline Career-related trauma & $1.43(0.99-2.1)$ & $1.59(0.97-2.6)$ & $1.10(0.6-2.1)$ \\
\hline Child abuse & $2.21(1.9-2.6)$ & $2.47(2.0-3.1)$ & $2.60(1.8-3.8)$ \\
\hline $\begin{array}{l}\text { 4. Career-related trauma } \times \\
\text { child abuse }\end{array}$ & $0.65(0.3-1.3)$ & $0.40(0.1-1.3)$ & $0.63(0.2-2.6)$ \\
\hline \multicolumn{4}{|c|}{$\begin{array}{l}\text { Note: } \mathrm{Cl}=\text { confidence interval, } \mathrm{OR}=\text { odds ratio. } \\
{ }^{*} \mathrm{Model} \mathrm{s} 1 \text { and } 2 \text { : adjusted for sex, age, marital status, region of residence, ethnicity, education, years of service and public } \\
\text { safety personnel category; model } 3 \text { : adjusted for the same variables as in models } 1 \text { and } 2 \text { with the addition of career-related } \\
\text { trauma and child abuse in the same model; model } 4 \text { : adjusted for the same variables as in model } 3 \text { with the main effects of } \\
\text { career-related trauma and child abuse in addition to the interaction term for career-related trauma } \times \text { child abuse. }\end{array}$} \\
\hline
\end{tabular}

\section{Strengths and limitations}

Strengths of our study include a large, diverse Canadian public safety personnel sample, which presented a comprehensive picture of the relations between a history of child abuse, career-related trauma and suicidal behaviours and facilitated comparisons across multiple public safety personnel categories. However, our results are subject to several limitations. First, cross-sectional data prohibit causal inferences. Second, the measure of child abuse was limited to experiences before the age of 16 years, but suicidal behaviour was measured over the lifetime, prohibiting discussions of temporality. Third, participation was voluntary, self-selected and online, and the data were retrospective, potentiating recall and response biases. The survey used a convenience sample - that is, potential participants were invited to participate through widely distributed emails and public service announcements and thus we are unable to determine the exact number who were successfully invited to participate and cannot compute a traditional response rate. Fourth, the low completion rate increases the possibility of response bias; however, the completion rate sensitivity analysis indicated significant differences on only a few variables. Fifth, the length of the survey may have contributed to respondent burnout and a reduced completion rate. Sixth, we did not adjust for several residual confounders, including, but not limited to, parental mental disorders, child poverty, access to health care, respondents' current or previous mental disorders and social support. Seventh, because we did not assess the frequency of suicidal behaviour, we do not know the persistence or severity of suicidality. Finally, the career-related trauma questions were designed specifically for this survey and have not been validated.

\section{Conclusion}

The high prevalence of a history of child abuse among a large sample of Canadian public safety personnel signals the need for stronger strategies to prevent child abuse and positive parenting interventions. Both a history of child abuse and career- related trauma were significantly related to suicidal behaviours; however, the relations were stronger for the former. Reducing child abuse may also reduce suicidal ideation, plans and attempts among Canadian public safety personnel. Our findings are important for developing effective treatment and intervention strategies aimed at reducing suicide among public safety personnel.

\section{References}

1. Oliphant R [chair]. Healthy minds, safe communities: supporting our public safety officers through a national strategy for operational stress injuries. Report of the Standing Committee on Public Safety and National Security. 42nd Parliament, first sess. Ottawa: House of Commons; 2016.

2. Carleton RN, Afifi TO, Turner S, et al. Mental disorder symptoms among public safety personnel in Canada. Can 7 Psychiatry 2018;63:54-64.

3. Violanti JM, Fekedulegn D, Charles LE, et al. Suicide in police work: exploring potential contributing influences. Am 7 Crim fustice 2009;34:41-53.

4. Nock MK, Hwang I, Sampson N, et al. Cross-national analysis of the associations among mental disorders and suicidal behavior: findings from the WHO World Mental Health Surveys. PLoS Med 2009;6:e1000123.

5. Carleton RN, Afifi TO, Turner S, et al. Suicidal ideation, plans, and attempts among public safety personnel in Canada. Can Psychol 2018;59:220-31.

6. Sareen J, Afifi TO, Taillieu T, et al. Trends in suicidal behavior and use of mental health services in Canadian military and civilian populations. CMAJ 2016;188:E261-7.

7. Komarovskaya I, Maguen S, McCaslin SE, et al. The impact of killing and injuring others on mental health symptoms among police officers. 7 Psychiatr Res 2011;45:1332-6.

8. Stanley IH, Hom MA, Joiner TE. A systematic review of suicidal thoughts and behaviors among police officers, firefighters, EMTs, and paramedics. Clin Psychol Rev 2016;44:25-44.

9. Weiss DS, Brunet A, Best S, et al. Frequency and severity approaches to indexing exposure to trauma: the Critical Incident History Questionnaire for police officers. 7 Trauma Stress 2010;23:734-43.

10. Violanti JM. Predictors of police suicide ideation. Suicide Life Threat Behav 2004; 34:277-83.

11. Sareen J, Afifi TO, Taillieu T, et al. Deployment-related traumatic events and suicidal behaviours in a nationally representative sample of Canadian Armed Forces personnel. Can 7 Psychiatry 2017;62:795-804.

12. Boulos D, Zamorski MA. Deployment-related mental disorders among Canadian Forces personnel deployed in support of the mission in Afghanistan, 2001-2008. CMA7 2013;185:E545-52.

13. Bryan CJ, Griffith JE, Pace BT, et al. Combat exposure and risk for suicidal thoughts and behaviors among military personnel and veterans: a systematic review and meta-analysis. Suicide Life Threat Behav 2015;45:633-49.

14. Sareen J, Cox BJ, Afifi TO, et al. Combat and peacekeeping operations in relation to prevalence of mental disorders and perceived need for mental health care. Arch Gen Psychiatry 2007;64:843-52. 
15. Schoenbaum M, Kessler RC, Gilman SE, et al. Predictors of suicide and accident death in the Army Study to Assess Risk and Resilience in Servicemembers (Army STARRS): results from the Army Study to Assess Risk and Resilience in Servicemembers (Army STARRS). FAMA Psychiatry 2014;71:493-503.

16. Stanley IH, Hom MA, Spencer-Thomas S, et al. Suicidal thoughts and behaviors among women firefighters: an examination of associated features and comparison of pre-career and career prevalence rates. 7 Affect Disord 2017;221: 107-14.

17. Afifi TO, MacMillan HL, Boyle M, et al. Child abuse and mental disorders in Canada. CMA7 2014;186:E324-32.

18. Afifi TO, Taillieu T, Zamorski MA, et al. Association of child abuse exposure with suicidal ideation, suicide plans, and suicide attempts in military personnel and the general population in Canada. FAMA Psychiatry 2016;73:229-38.

19. Scott KM, Smith DR, Ellis PM. Prospectively ascertained child maltreatment and its association with DSM-IV mental disorders in young adults. Arch Gen Psychiatry 2010;67:712-9.

20. Borges G, Nock MK, Haro Abad JM, et al. Twelve-month prevalence of and risk factors for suicide attempts in the World Health Organization World Mental Health Surveys. 7 Clin Psychiatry 2010;71:1617-28.

21. Dube SR, Anda RF, Felitti VJ, et al. Childhood abuse, household dysfunction, and the risk of attempted suicide throughout the life span. $7 A M A 2001 ; 286$ : 3089-96.

22. McLaughlin KA, Green JG, Gruber MJ, et al. Childhood adversities and adult psychiatric disorders in the National Comorbidity Survey Replication II: associations with persistence of DSM-IV disorders. Arch Gen Psychiatry 2010;67:124-32.

23. Kessler RC, McLaughlin KA, Green JG, et al. Childhood adversities and adult psychopathology in the WHO World Mental Health Surveys. Br 7 Psychiatry 2010;197:378-85.

24. Turner RJ, Lloyd DA. Lifetime traumas and mental health: the significance of cumulative adversity. 7 Health Soc Behav 1995;36:360-76.

25. Stein DJ, Chiu WT, Hwang I, et al. Cross-national analysis of the associations between traumatic events and suicidal behavior: findings from the WHO World Mental Health Surveys. PLoS One 2010;5:e10574.

26. Komarovskaya I, Brown AD, Galatzer-Levy IR, et al. Early physical victimization is a risk factor for posttraumatic stress disorder symptoms among Mississippi police and firefighter first responders to Hurricane Katrina. Psychol Trauma 2014;6:92-6.

27. Walsh CA, MacMillan HL, Trocmé N, et al. Measurement of victimization in adolescence: development and validation of the Childhood Experiences of Violence Questionnaire. Child Abuse Negl 2008;32:1037-57.

28. Canadian Community Health Survey (CCHS) - Mental Health questionnaire. Ottawa: Statistics Canada; 2011. Available: http://www23.statcan.gc.ca/imdb/ p2SV.pl? Function=getSurvey\&Id=5285 (accessed 2018 Feb. 15).

29. Canadian Forces Mental Health Survey questionnaire. Ottawa: Statistics Canada; 2013. Available: http://www23.statcan.gc.ca/imdb/p2SV.pl?Function= getSurvey\&SDDS=5084 (accessed 2018 Feb. 15).

30. Brown JJ, Freeman C, Flynn B, et al. Integration in the emergency operations centre (EOC)/emergency communications centre (ECC). In: Flynn B, Sherman R, editors. Integrating emergency management and disaster behavioral health: one picture through two lenses. 1st ed. New York: Elsevier; 2017:255-76.

31. Canadian Community Health Survey (CCHS) - Mental Health user guide. Ottawa: Statistics Canada; 2013.

32. Stein M, Campbell-Sills L, Ursano R, et al. Childhood maltreatment and lifetime suicidal behaviours among new soldiers in the US Army: results from the Army Study to Assess Risk and Resilience in Servicemembers (Army STARRS). $\mathcal{f}$ Clin Psychiatry 2018;79:pii:16m10900.
33. Stanley IH, Hom MA, Hagan CR, et al. Career prevalence and correlates of suicidal thoughts and behaviors among firefighters. 7 Affect Disord 2015;187: 163-71.

34. Chopko BA, Palmieri PA, Facemire VC. Prevalence and predictors of suicidal ideation among U.S. law enforcement officers. 7 Police Crim Psychol 2014;29:1-9.

Affiliations: Departments of Community Health Sciences (Turner, Sareen, Afifi), Psychiatry (Turner, Sareen, Afifi) and Psychology (Sareen) and the Applied Health Sciences Program (Taillieu), University of Manitoba, Winnipeg, Man.; Department of Psychology (Carleton), University of Regina, Regina, Sask.

Contributors: Sarah Turner, Tamara Taillieu, Nicholas Carleton and Tracie Afifi conceived the study and contributed to the study design. Sarah Turner and Tamara Taillieu analyzed the data, supervised by Nicholas Carleton and Tracie Afifi. Jitender Sareen provided feedback on the analytical approach. Sarah Turner drafted the manuscript, and Tamara Taillieu, Nicholas Carleton, Jitender Sareen and Tracie Afifi critically revised it for important intellectual content. All of the authors contributed to data interpretation, gave final approval of the version to be published and agreed to be accountable for all aspects of the work.

Acknowledgements: Special thanks for recruitment support provided by (in alphabetical order) Badge of Life Canada, Behind the Red Serge, the Canadian Association for Police Governance, the Canadian Association of Chiefs of Police, the Canadian Association of Fire Chiefs, the Canadian Institute for Military and Veteran Health Research, the Canadian Ministry of Public Safety and Emergency Preparedness, the Canadian Police Association, the Community Safety Knowledge Alliance, the Correctional Service of Canada, Families of the RCMP for PTSD Awareness, the First Responder Mental Health Network Collaboration, the International Association of Fire Fighters, the Justice Institute of British Columbia, the Mental Health Commission of Canada, the Mood Disorders Society of Canada, the Nova Scotia Operational Stress Injury Clinic - Capital Health, the Paramedic Association of Canada, Paramedic Chiefs of Canada, the Royal Canadian Mounted Police, the Tema Conter Memorial Trust, the Union of Solicitor General Employees and Wounded Warriors Canada.

Funding: Tracie Afifi's research is supported by a Canadian Institutes of Health Research (CIHR) New Investigator Award and a CIHR Foundation Scheme Award. Nicholas Carleton's research is supported by the CIHR through New Investigator Award FRN:285489. Jitender Sareen's research is supported by CIHR Foundation Scheme Award FRN:333252. This research was funded in part by the Ministry of Public Safety and Emergency Preparedness through the Policy Development Contribution Program.

Supplemental information: For reviewer comments and the original submission of this manuscript, please see www.cmajopen.ca/content/6/4/ E463/suppl/DC1. 